DOI: http://dx.doi.org/10.11606/issn.1984-4867.v26i4p817-842

\title{
Planeamento Turístico e Impactos Percecionados na Ilha da Boa Vista, Cabo Verde
}

\author{
Tourism Planning and Perceived Impacts on the Island of Boa Vista, Cape Verde \\ Planificación de la oferta Turística y sus impactos percibidos en la isla de Boa Vista, Cabo \\ Verde
}

Edgar Bernardo ${ }^{1}$

\section{Resumo}

Em busca de um modelo de desenvolvimento sustentável que potencie as suas características morfológicas e climáticas, Cabo Verde viu no turismo massificado a resposta para as suas precariedades. De entre as ilhas escolhidas para a aplicação deste plano encontra-se a Boa Vista, um espaço que historicamente tem sido sinónimo de periferia nacional e de produção primária de subsistência. Nas duas últimas décadas este espaço tem sido um palco privilegiado pelos vários Governos para a aplicação da planificação turística centralizada. Uma planificação assente no turismo balnear massificado em serviço de turistas europeus. Este trabalho apresenta as perceções da comunidade residente da ilha quanto aos impactos positivos e negativos promovidos por esta aposta. Estas perceções foram recolhidas através da aplicação de entrevistas semi-dirigidas e procuram contribuir para determinar se o turismo, planeado desde o centro, tem contribuído para solucionar as precariedades e carências da Boa Vista, e os o objetivos de Cabo Verde. De entre os resultados salienta-se o volume de impactos positivos do tipo económico e entre os negativos os sociais.

Palavras-Chave: Turismo; Desenvolvimento; Impactos; Perceções; Boa Vista.

\begin{abstract}
In search of a sustainable development model, Cape Verde saw on mass tourism the answer to escape their precariousness and potentiate its morphological and climatic characteristics. Among the islands chosen for the implementation of this plan is Boa Vista, an island that has historically been synonymous with national periphery and primary subsistence production. In the last two decades this island has been a privileged stage for the implementation of centralized tourist planning by various governments. A planning based on mass-beach tourism in service of European tourists. This paper presents the perceptions of residents of the island community on the positive and negative impacts promoted by this tourism. These perceptions were collected by applying semi-structured interviews and seek to help determine

1 Doutorando em Sociologia pelo ISCTE-Instituto Universitário de Lisboa. Investigador do Centro de Investigação e Estudo de Sociologia do Instituto Universitário de Lisboa (CIES-IUL). Lisboa, Portugal. Email:edgaruxico@hotmail.com
\end{abstract}


whether tourism, planned from the center, has helped to address the precarious and needs of Boa Vista, Cape Verde and the goals. Among the results we underline the econmic impacts on the positive side, and social impacts on the negative side.

Keywords: Tourism; Development; Impacts; Perceptions; Boa Vista.

\section{Resumen}

En busca de un modelo de desarrollo sostenible, Cabo Verde vio en el turismo de masas la respuesta para escapar a su precariedad y la potenciación de su características morfológicas y climáticas. Entre las islas elegidas para la ejecución de este plan es Boa Vista, una isla que ha sido históricamente sinónimo de periferia nacional y la producción primaria de subsistencia. En las dos últimas décadas esta zona ha sido un escenario privilegiado por varios gobiernos para la aplicación de la planificación turística centralizado. Una planificación basada en el turismo de masas-playa en el servicio de los turistas europeos. Este artículo presenta las percepciones de los residentes de la comunidad de la isla sobre los impactos positivos y negativos promovidos por esta apuesta. Estas percepciones se recogieron mediante la aplicación de entrevistas semiestructuradas y buscar ayuda a determinar si el turismo, planificada desde el centro, ha ayudado a hacer frente a la precariedad y las necesidades de Boa Vista, Cabo Verde y las metas. Entre los resultados reforzar el volumen de los impactos positivos de tipo económico y entre lo negativo social.

Palabras clave: Turismo; Desarrollo; Impactos; Percepciones; Boa Vista.

\section{Introdução}

Enquanto Pequeno Estado Insular, Cabo Verde é um exemplo de um país fechado num modelo de integração designado MIRAB. Originalmente sugerido por Bertram e Watters (1986), procurava caracterizar as sociedades das ilhas do pacífico como pequenas economias insulares dependentes de acentuados fluxos migratórios (MI), das remessas dos trabalhadores emigrados (R), da ajuda pública externa para financiar as despesas públicas (A), e de uma pesada máquina de burocracia administrativa (B). Estes autores argumentariam que este sistema MIRAB não se trata de uma fase, mas sim de uma estratégia viável a longo prazo, que pretende utilizar a ajuda externa para equilibrar a Balança de Pagamentos, e complementá-la com as remessas enviadas pela população emigrada.

A questão é, então, como desenhar uma estratégia que permita escapar às debilidades deste sistema e simultaneamente potenciar as vantagens de forma sustentável. Para Sarmento (2008), a resposta reside na criação e reforço da dinâmica do exterior para o interior, isto é, 
pela captação do mercado mundial através do turismo.

Tal esforço exige um equilíbrio delicado, cuja sustentabilidade depende de uma planificação e execução consciente e adequada. A chave da sustentabilidade em Cabo Verde parece residir em parte na capacidade de gerir os frágeis territórios insulares com capital natural limitado, transformando vantagens comparativas e competitivas. Daí que autores como Vellas (1997), Kakazu (2007), e Sarmento (2008), afirmarem que a exportação de serviços poderá ser a estratégia ideal. Dado o vastíssimo conjunto de vantagens previstas pelos autores é compreensível a escolha do turismo como estratégia por parte tanto de privados como do sector público.

O turismo força a uma interação vasta entre pessoas e exige uma variedade de serviços, infraestruturas e investimentos que permitam gerar e aproveitar oportunidades. É necessário gerir o crescimento e as mudanças do turismo, de modo a garantir que o crescimento deste não afeta os objetivos estabelecidos para o crescimento ao nível local e nacional.

Em particular nas economia mais frágeis dos países em vias de desenvolvimento, o turismo não é uma formula mágica que garante crescimento ou desenvolvimento imediato (Brown, 1998). Entre os países africanos o veredito sobre o sucesso da sua implementação é algo discutível dada a disparidade entre os resultados das estatísticas globais desses países, e as consequências regionais e locais do turismo nesses territórios e nas suas comunidades.

Nestes destinos muitas vezes são apenas as elites e a classe média, lideres políticos e os mais ricos, que beneficiam de um aumento dos seus rendimentos através deste tipo de processos de desenvolvimento através do turismo (Azarya, 2004). Situação que leva inúmeros autores a rotular o turismo como uma forma de exploração e dependência que se assemelha ao neocolonialismo (Dieke, 2003).

Estas afirmações resultam, em parte, do afastamento das populações mais pobres das decisões, e da sua incapacidade perante a nova realidade, preferindo benefícios económicos imediatos à custa de uma sustentabilidade a longo prazo. Condição que surge como fruto da sua "egoísta luta pela sobrevivência" que relega para segundo plano ideias como o altruísmo ou a sustentabilidade (Redclift, 1992).

Por turistificação entendemos o processo pelo qual um dado destino, comunidade, 
característica ou traço cultural, ou património, são transformados, desde o centro de decisão política e/ou privada, num produto turístico para o consumo massificado. Uma turistificação transparente, capaz de seguir o fluxo do dinheiro do turismo na sua suposta redistribuição justa pela comunidade, tem de acompanhar as implicações do turismo passo a passo, sejam elas positivas ou negativas. A turistificação de um destino e respetiva comunidade, dependem de uma acompanhamento transparente dos fluxos de capital (Okecha e Mwagona, 2007).

O desenvolvimento promovido através da aposta no turismo internacional em África, ou em qualquer outro continente, tem de ter em conta os impactos que inflige nas populações mais pobres e qual a melhor forma de, envolvendo essas mesmas populações, desenhar o roteiro para uma sociedade mais justa e equitativa. Só nestas condições podemos declarar o intuito de procurar atingir um desenvolvimento sustentável, ou um turismo sustentável.

As narrativas estatais e de organismos supranacionais de um desenvolvimento sustentável alavancado no turismo internacional, encontram-se enraizadas nos discursos e planeamento dos governos de muitos países em vias de desenvolvimento. Cabo Verde é apenas um exemplo da dispersão messiânica do desenvolvimento pela turistificação.

Tais pressupostos, planos e princípios desenvolvimentistas estão condenados se não existir uma particular atenção à capacitação contínua dos recursos humanos, nomeadamente ao empowerment local ou comunitário. O aproveitamento de oportunidades de negócio ao nível local, e consequente retenção dos capitais resultantes do turismo nas comunidades, é a chave para travar ou mitigar muitos impactos e consequências negativas desse processo.

Um dos maiores desafios do turismo em África é a capacitação das pequenas e médias empresas locais de turismo, para que estas sejam capazes de escapar a uma situação de precariedade, e perda de qualidade do serviço prestado, e conseguir investir em estratégias bem sucedidas de captação de clientes/turistas.

Este trabalho pretende dar a conhecer o quadro geral da situação caboverdiana, em particular, dar a conhecer a sua abertura aos mercados internacionais, desde a década de 1990. Seguidamente, contextualiza o caso da ilha da Boa Vista, e apresenta os impactos que, desde a perspetiva da comunidade local, são fruto da turistificação da ilha. Finalmente, encerra com a problematização dos resultados na conclusão. 


\section{Modelo de Desenvolvimento Caboverdiano (1975-2013)}

A rota para o turismo internacional massificado como alavanca para o desenvolvimento do arquipélago está inscrita em parte nos sucessivos Planos Nacionais de Desenvolvimento (PND). O $1^{\circ}$ Plano Nacional de Desenvolvimento (1982-1985), alertava desde logo para as dificuldades que o país enfrentava, não só as que derivavam de uma independência recente, como as que advinham de uma localização periférica face ao continente africano, e da dispersão geográfica do arquipélago.

As medidas concretas propostas assentavam num modelo económico focado da industrialização nacional e na aposta no mercado interno, criando condições de base que permitissem escapar ao modelo MIRAB. Contudo, a dependência face à ajuda externa manteve-se como principal, e quase única, fonte de acumulação.

O $2^{\text {a }}$ PND (1986-1990) reunia como principais objetivos criar uma base económica sólida de forma a permitir estabilizar a produção, e como medidas concretas apontava já para uma preocupação social clara, com intenções de equidade social, criação de emprego e construção de infraestruturas. Dois planos que na teoria e na prática seguiam um modelo económico e social pró-soviético isolacionista.

No ano de 1991 decorreram em Cabo Verde as primeiras eleições legislativas que colocariam no poder o Movimento para a Democracia (MpD). O novo governo procurou sobretudo apontar baterias para o sistema económico mundial e nesse sentido o $3^{\circ}$ PND (1992-1995), apostou num mercado externo, numa dinâmica que procurava inserir o país no mercado global através do incentivo do investimento privado e liberalização da economia. No $4^{\circ}$ PND (19972000) assistiu-se a um reforço desta postura de liberalização (através da privatização de empresas públicas, por exemplo) e aposta na economia internacional. Neste foi aberta a porta para o investimento privado e reduzida a intervenção estatal, criada a Lei Base do Turismo, e disponibilizaram-se cerca de $10 \%$ das verbas para a aplicar ao Turismo.

No $5^{\circ}$ PND, 2002-2005, implementado pelo PAICV, procurou-se executar os seguintes subprogramas: aumento da eficiência da administração pública; diversificação dos produtos turísticos; formação de recursos humanos para o sector; desenvolvimento do turismo da Boa 
Vista e do $\mathrm{Maio}^{2}$; uma planificação turística mais eficaz na promoção de investimentos no sector e que assegure um desenvolvimento sustentável do turismo na ilha do Sal e nas ZTE ${ }^{3}$. Há que referir ainda a criação de uma Escola de Hotelaria e de um Instituto Superior de Turismo e Hotelaria, para além de intenções expressas para a promoção do eco-turismo, turismo de habitação, entre outras formas de turismo.

Os primeiros grandes resultados deste percurso chegaram em 2007. O turismo atingiu um volume de receitas correspondente a $23 \%$ do PIB do país, e foi responsável por $90 \%$ dos investimentos externos $\left(\mathrm{CCIT}^{4}\right)$. O país recebeu de 333 mil turistas em 2007, quando em 1990 havia recebido pouco mais e 21 mil turistas (INE-CV, 2015). Esta rápida ascensão demonstra o impacto de uma aposta de fundo no sector. No ano seguinte, os principais emissores de turistas foram o Reino Unido, Itália e Portugal, estes totalizando 56,7\% do total de turistas (INE-CV, 2015).

O crescimento e desenvolvimento do país foi, e ainda é, uma bandeira política sinónimo de sucesso. Basta rever as palavras do Primeiro Ministro de Cabo Verde, José Maria das Neves, quando se dirigiu à sua nação em Julho de 2010, "Cabo Verde manteve taxas de crescimento robustas. O PIB cresceu em média 7,3\% por ano entre 2006 e 2009. Já em 2006 atingimos a taxa de crescimento de $10,1 \%$. A crise internacional veio contrariar essa expansão. Mesmo assim, continuamos com bons índices de crescimento" (Neves, 2010:2).

A ideia de potenciar a exploração do turismo foi também apontada como desejo e meta a atingir a curto prazo pelo Governo. Nesta linha, é importante mencionar os pontos chave do plano para 2011-2016, presente no documento oficial "Programa do Governo VIII Legislatura 2011-2016"5. Desde logo, uma continuidade na abertura aos mercados internacionais, o desenvolvimento do sector privado e reformas no sector público, também medidas que vão ao encontro das palavras citadas do líder do Governo, como as questões sociais, inclusão e coesão. Ainda a continuidade na aposta educativa e na construção de infraestrutura (saneamento, energia, mas também as que permitam maior mobilidade entre ilhas e para o exterior, nomeadamente, para os países de onde provém o mercado turístico).

\footnotetext{
Em 2005 é criada a Sociedade Desenvolvimento das Turístico das Ilhas da Boa Vista e Maio (SDTIBM).

Zonas Turísticas Especiais.

4 Câmara de Comércio, Indústria e Turismo Portugal Cabo Verde (http://www.portugalcaboverde.com/main.php).

5 Ofício de 14 de Junho de 2011.
} 
Temos de destacar as infraestruturas de base que existem atualmente e que são originárias do investimento e aposta no turismo, desde aeroportos, estradas, saneamento, eletricidade, transportes, formação e qualificação de pessoas, etc. E claro, os dados sociais e económicos que sugerem uma melhoria profunda quando comparados com os de 1975, ou mesmo de 2000.

De acordo com o índice as Nações Unidas, Cabo Verde é já um país de Médio Desenvolvimento. O país fez enormes progressos ao nível económico e social. A esperança média de vida aumentou, a taxa de mortalidade diminuiu. Os avanços nas áreas de saúde e até educação mostram os progressos realizados pelo país que, para tudo isto alcançar, investiu muitos milhões de euros de dívida pública. Sacrifício que tenta ser suportado por toda esta aposta na turistificação de algumas das suas ilhas, em particular a ilha do Sal e da Boa Vista.

Entre 2000 e 2012, o número de hóspedes como o número de dormidas a nível nacional aumentaram, o número de hóspedes mais do que triplicou, o número de dormidas pentaplicou, passando de 684 mil dormidas para as 3,33 milhões (INE-CV, 2015)! Desde 2010 apresenta ainda uma estável percentagem de ocupação acima dos 50\%, hospedando atualmente mais de 550 mil hóspedes (INE-CV, 2015). Não é comum uma ocupação elevada nos primeiros anos de abertura, com exceção talvez para os grandes empreendimentos hoteleiros do tipo tudoincluído. Na ilha da Boa Vista, a construção do aeroporto internacional que abre em 2007, bem como de alguns hotéis terminados em 2010, catapultaram a taxa de ocupação.

O turismo hoteleiro, em particular, o turismo hoteleiro assente numa política de tudo-incluído é o grande responsável por assegurar estes clientes/turistas. Com a abertura aos mercados internacionais, garantindo condições vantajosas para os investidores estrangeiros, o turismo em Cabo Verde tornou-se a atividade económica mais importante do país. O turismo internacional é a principal alavanca económica que prometia ser, um farol para a economia do arquipélago que sente o seu efeito multiplicador para além das naturais remessas diretas recolhidas centralmente pelo governo.

O turismo parece vingar e a resposta poderá residir nos elementos diferenciadores que dispõe, nomeadamente, a estabilidade política, económica e social que vive, os bons indicadores económicos que apresenta, a proximidade face aos principais mercadores, sobretudo europeus. Podemos ainda destacar o seu posicionamento geográfico com potencial de captar 
novos mercados nos continentes americano e africano, e ainda, claro, as temperaturas médias que apresenta $\left(25^{\circ} \mathrm{c}\right)$.

\section{Da Boa Vista Descoberta a Cabo Verde Independente}

Esta investigação ocupou-se do estudo de caso da ilha da Boa Vista. Esta ilha de $620 \mathrm{~km}^{2}$ e de clima ameno ao longo de todo o ano, está repleta de longas e belas praias sendo a maior Santa Mónica com $18 \mathrm{~km}$ de comprimento. Foi descoberta pelos portugueses a 3 de Maio de 1460 e povoada apenas no final do século XVI. Enquanto a ilha mais oriental do arquipélago é também a que está mais próxima do território continental africano.

A Boa Vista é conhecida sobretudo pela suas características morfológicas e por ser o berço da 'morna', estilo musical com influência afro-negra. A história escrita sobre esta ilha, pela escassez de registos históricos e obras publicadas sobre a sua história e cultura, é uma sombra da sua riqueza cultural e património histórico ${ }^{6}$.

São conhecidas as dificuldades históricas da população da ilha em sobreviver nas difíceis condições climáticas da Boa Vista, forçando algumas vezes as suas populações a migrar, escapando à fome e à miséria. Foram essas características deste povo que o acabaram por moldar de forma diferente das outras ilhas, a que Lima (2002) chamou de "um perfil psicosociológico específico". Ainda assim, em paralelo com as suas dificuldades, é ainda tido como um povo alegre cuja alcunha Kabrere terá originado da comercialização de gado caprino. Alcunha essa que é tida ainda hoje com motivo de orgulho.

No que se refere às riquezas do solo, a Boa Vista foi desde cedo identificada como tendo grande potencial para a produção de gado dada a grande estepe de vegetação que a época das chuvas permitia, ideal para a pastagem. Para além da pastorícia também alguma plantação de algodão foi implementada na ilha sem grande sucesso. Na verdade, o auge económico da ilha surgiu apenas no início do século XVII com a chegada dos ingleses à ilha. Estes iniciaram a exploração das salinas de Sal-Rei e a produção de urzela para a indústria têxtil. A saída de famílias preponderantes em função de promessas de melhor investimento na ilha de S.

6 Dos poucos autores que compilaram um levantamento de nota foram António Germano Lima (1997; 2002) e João Lopes Filho (1976) 
Vicente (e noutras paragens), onde um novo porto faria redundar a preponderância do porto de Sal-Rei, acabou por ditar um novo e lento declínio económico e social da ilha. Período seguido por uma forte migração da população local para outras ilhas e países, provocando um sentido êxodo migratório que lentamente afundou a frágil economia local até à independência, em $1975^{7}$.

Da emigração forçada, às catástrofes naturais e humanas, da crise do império português cujos ideais se arrastaram no Estado Novo, a Boa Vista sofreu uma fuga de capital cultural, social e humano, nas décadas anteriores e posteriores à sua independência. O pós-independência é precisamente o período de maior interesse nesta investigação daí que, sugerimos uma leitura aprofundada de Lima (2002) para um olhar mais minucioso à história da Boa Vista até esta data.

Os primeiros visitantes pós-independência foram os voluntários franceses que num protocolo de apoio médico passavam algumas semanas por ano na ilha. $\mathrm{O}$ seu acampamento de apoio médico era montado no exterior do centro da cidade, hoje junto aos novos bairros edificados para alojar turistas de residência na praia de Cruz. Gradualmente estes visitantes foram ultrapassados pelos turistas de aventura que chegavam à ilha de barco, em embarcações particulares ou de voos de domésticos via Sal.

Com as primeiras eleições multipartidárias livres, em 1992, e criada a base para o investimento público-privado no turismo e serviços dependentes, a Boa Vista viu a gradual e consistente chegada de turistas. Isto conduziu à construção do primeiro Hotel de dimensões médias na ilha e, à data, um dos maiores do país, o Marine Club.

Para muitos locais os dois pontos altos para a ilha na década no pós independência foram sem dúvida a construção do Marine Club e a eletrificação da ilha. Ainda que no caso da eletrificação muitos sublinham que esta apenas foi acelerada por pressão dos emigrantes que por iniciativa privada já começavam a procurar instalar a rede elétrica em algumas povoações.

Este hotel sem regime tudo-incluído foi rapidamente acompanhado e seguido por outros novos pequenos hotéis e residenciais em Sal-Rei, sendo um período rotulado pelos locais como o "bom turismo", em oposição ao turismo que conheceram depois de 2006. Este

População Recenseada em 1970 era de 3569 habitantes, número que diminuiria para os 3375 dez anos mais tarde (1980) [citado por Lima, 1997:73]. 
período de "bom turismo" foi caracterizado ainda pela presença de empresas e investimento privado italiano para turistas italianos.

A hegemonia italiana, apesar de curta duração, teve um profundo impacto na economia e cultura local. Inúmeros funcionários das empresas que inicialmente investiram na ilha, são hoje empresários de sucesso que conseguiram aproveitar as oportunidades de negócios que se multiplicaram com a abertura ao turismo internacional.

O referido "bom turismo", época dourada de desenvolvimento económico local e de muitas oportunidades para os nativos da ilha, é comummente comparado com o turismo pós-2006, classificado como "mau turismo", ou seja, o turismo massificado de serviço tudo-incluído que chegou com a expansão do aeroporto e com a construção dos primeiros hotéis com regime tudo-incluído, nomeadamente o Ventaclub e o Riu Karamboa.

Olhando para os últimos sete anos na Boa Vista podemos verificar como o número de hotéis, da pequena à grande dimensão, se multiplicaram. A ilha passou a pertencer ao circuitos comuns de turismo internacional, em particular Europeu, em grande parte pela mão de grandes operadores, com destaque para a TUI. Esta empresa alemã é responsável pelo grosso dos turistas do centro e norte da Europa, em particular do Reino Unido, Alemanha e países nórdicos.

\section{Método}

Descrito o objeto de estudo deste trabalho, passemos à contextualização da própria investigação e metodologia. Este artigo enquadra-se numa investigação aos discursos, impactos e reações ao turismo na ilha da Boa Vista em Cabo Verde. Um projeto financiado pela Fundação para a Ciência e Tecnologia de Portugal e no âmbito do programa de doutoramento em Sociologia do investigador, este associado ao Centro de Investigação e Estudos em Sociologia do Instituto Universitário de Lisboa.

A metodologia selecionada foi de cariz qualitativo, ou intensivo, envolvendo o investigador na comunidade boavistense entre 2012-2014, durante mais de catorze meses, e do qual resultaram um conjunto de entrevistas semi-dirigidas, cujo bloco central do guião, se prendia 
com a perceção dos residentes da comunidade local sobre os impactos do turismo na ilha e na sua comunidade.

Quanto à amostra, esta é caracterizada por 96 indivíduos, 58 dos quais do género masculino, cerca de 60,4\%, e os restantes do género feminino. Em termos de proveniência, 78,1\% são nativos de Cabo Verde, 19,8\% são oriundos da Europa (Portugal, Espanha, França, e Itália), e os restantes 2,1\% provenientes de outros países (um do Brasil, outro de Angola).

Em termos de residência, a maioria dos entrevistados habita em espaço urbano $(71,9 \%)$ e os restantes em espaço rural. A escolaridade foi outra das características sócio-demográficas recolhidas. Esta foi dividida em 6 categorias, começando no "ensino primário incompleto" até "ensino superior". Aqui reuniram-se um grande número de entrevistados enquadrados na categoria "ensino superior", cerca de 46,9\%. Isso justifica-se pela maioria dos elementos estrangeiros, operadores, e intervenientes políticos entrevistados terem formação superior, assim como, alguns dos residentes naturais da Boa Vista e das outras ilhas serem professores do ensino secundário.

No que se refere à idade, esta considerou apenas indivíduos adultos, tendo o mais novo 20 anos e o mais velho mais de 70 anos. Dessa forma, subdividiram-se os entrevistados em 6 categorias $(20-29,30-39,40-49,50-59,60-69,70+)$. A característica seguinte refere-se à situação profissional. Esta considerou 5 categorias: "empregado" (64,6\%), “desempregado"(5,2\%), "trabalhador por conta própria" (22,9\%), "reformado" (6,3\%), e “doméstico" (1\%). Já a última característica sócio-demográfica considerada foi o "Grupo". Esta refere-se à origem dos residentes (naturais da Boa Vista, de outras ilhas, e estrangeiros residentes) considerando ainda a categoria de "operadores". Aqui, destacamos a prevalência de "residentes naturais da Boa Vista" que representa cerca de $61,5 \%$, sendo as restantes muito aproximadas em percentagem, variando entre os 11,5\% dos "operadores" e os 14,6\% dos "residentes estrangeiros".

Esta amostra assumiu uma maior prevalência da parte dos residentes naturais da Boa Vista, pois um dos seus objetivos era determinar as perceções destes nativos, isto apesar de, à partida, de acordo com os dados estatísticos disponíveis, a maioria da população ser já originária de outras ilhas, por uma curta margem. Todavia, no terreno, verificou-se que os dados estatísticos estavam profundamente desatualizados apesar de os mais recentes terem 
sido recolhidos para o Censos nacional de 2010, pois a população havia triplicado.

As entrevistas foram tratadas, e desenhou-se uma base dados em SPSS 20 assente nos impactos positivos e negativos de referência adaptados aos resultados e contexto. Deste resultaram os dados que são apresentados seguidamente e comparados com alguns resultados de outras investigações internacionais e apresentadas as respetivas ilações.

Resta referir que nesta investigação resultaram ainda dados referentes à perceção das: motivações dos turistas, da atitude face ao futuro, das prioridades de intervenção, e ainda, foram aplicados inquéritos a turistas de forma a determinar a sua avaliação à experiência turística na Boa Vista. Seguidamente avançamos a análise dos dados que seguirá bipartida iniciando pelos impactos positivos percecionados, e encerrará com os negativos. Os impactos seguem dos mais para os menos mencionados e são contextualizados pelo investigador.

\section{Impactos Positivos Percecionados pelos Residentes}

Os impactos positivos detetados foram onze sendo que os impactos ambientais detêm uma atenção marginal totalizando apenas $1 \%$. Já os impactos de cariz económico ocupam sem dúvida o lugar de destaque com $68 \%$ do total das referências. Os impactos sociais ocupam um lugar de médio destaque, com $31 \%$ das referências totais.

Ora, o impacto positivo mais mencionado é a 'criação de emprego'. Até à chegada do turismo à ilha, encontrar uma oportunidade de trabalho revelava-se extremamente complicado. Com o impulso da construção de infraestruturas para o turismo, e a chegada de novas empresas à Boa Vista, o cenário hoje é quase o oposto. Em menos de 20 anos a economia local melhorou significativamente e são inúmeras as oportunidades para trabalhar na ilha, tanto para locais, como para estrangeiros ou migrantes nativos. De acordo com os dados do World Travel \& Tourism Council, o emprego direto e indireto gerado pelo turismo no país no ano de 2014 foi de 79.500 empregos, cerca de 35,8\% do emprego nacional, e estima-se que em 2015 o turismo seja responsável por 41,5\%, chegando muito próximo dos 84 mil empregos. Salvo uma quebra em 2009 o emprego associado ao turismo tem crescido e só os empregos diretos 
chegaram aos $14,5 \%$ em $2013^{8}$. A criação de emprego é um fator incontornável e da maior importância para os entrevistados e os dados são quem o comprova, indo ao encontro de muitos outros estudos internacionais (como Milman e Pizman, 1988; Faulkner e Tideswell, 1997; Andriotis, 2008; Gu e Ryan, 2008; entre outros).

O segundo impacto positivo do turismo destacado é a 'infraestruturação', coincidindo com os trabalhos de referência de autores como Akis et al (1996), ou Ap e Crompton (1998), refere-se à edificação de estruturas vitais para a turistificação, como hotéis, aeroporto, etc.

A 'migração' para a Boa Vista surge na terceira posição dos impactos positivos percecionados pelos entrevistados. Esta força de trabalho que chega à ilha é composta inicialmente por migrantes nativos, em particular da ilha de Santiago, e gradualmente reforçada por gente de outras ilhas e de origens tão diferentes como alguns países da costa africana, como Senegal e Guiné, e da Europa, como Itália e Espanha, e também de nativos da Boa Vista que regressam em virtude das oportunidades que vão sendo criadas. A comunidade nativa representa hoje apenas um terço dos 12 mil habitantes da ilha. Estes dados encontram pouco paralelo direto com outras estudos. Isto leva-nos a considerar que, a determinação da migração como um aspeto positivo é algo aparentemente particular ou diferenciador deste estudo de caso para com outros 9 .

Para os entrevistados, assistiu-se a uma 'melhoria das condições de vida'. Considerámos aqui as alterações ao custo de vida, acesso a novos serviços ou a serviços melhorados, e aumento do poder de compra, etc. A edificação de um novo hospital, o aumento do pessoal no mesmo, e a expansão da escola da Boa Vista, são claros exemplos de indicadores dessa mesma melhoria das condições de vida verificadas naquele espaço, sendo novamente um outro impacto expectável de acordo com os resultados de, por exemplo, Liu e Var (1986), Akis et al (1996), Chen et al (2004).

O 'crescimento económico' é o impacto positivo que se segue e engloba novamente a multiplicação de novas empresas e oportunidades de negócio, mas também aumento do consumo, o acesso ao crédito, acesso a novos produtos e a redução do custo dos produtos. $\mathrm{O}$

\footnotetext{
Estes dados respeitam o relatório de 2014 do WTTC disponível em http://www.wttc.org.

9 Ainda assim, uma situação próximo à recolhida por Monterrubio et al (2012) no México, onde também membros de grupos culturais diferentes representam $70 \%$ da força de trabalho da comunidade de Huatulco.
} 
crescimento económico é uma realidade na ilha da Boa Vista, assim como se verificou nos trabalhos de Cooke (1982) ou Perdue et al (1990).

O 'intercâmbio cultural' é de complicada medição, sendo por tanto essencial que seja a experiência relativa dos entrevistados a medida desse intercâmbio que tanto pode ser positivo como negativo. Falamos de intercâmbio percecionado como positivo e que toma diferentes formas de acordo com os entrevistados, sendo as mais comuns a aprendizagem de novas línguas, novas tradições e costumes, e outros fatores que de alguma forma enriqueceram a comunidade e a transformaram. Contemplamos então os intercâmbios de natureza externa, tanto nacionais como internacionais. No caso deste impacto positivo é impossível determinar estatisticamente o grau de intercâmbio cultural pois trata-se de um impacto subjetivo e assim apenas determinável através de uma avaliação qualitativa que nos remete novamente para a subjetividade dos elementos afetos. É dizer, os únicos dados palpáveis acabam por ser as perceções dos próprios membros da comunidade. Complicando mais ainda esta questão há que considerar ainda que é extremamente difícil diferenciar o intercâmbio cultural motivado pelo turismo daquele motivado, por exemplo, pelo contacto com outras culturas através de meios de comunicação como a televisão ou Internet. Ainda assim um resultado semelhante aos de Milman e Pizam (1988), ou Ap e Crompton (1998).

O 'aumento dos níveis profissionais locais', prende-se com a capacitação profissional que a experiência e formação profissional no ramo da hotelaria e hospitalidade acarreta. As milhares de pessoas que direta e indiretamente trabalham com os turistas foram e são alvo de formação tanto por parte das empresas privadas que têm esse interesse de melhor servir os seus clientes, mas também por parte de outros organismos, como as associações de juventude, outros órgãos da câmara municipal da Boa Vista, e instituições privadas, como é o caso da $\operatorname{SDTIBM}^{10}$. Esta profissionalização pode implicar uma formação formal como informal, mas também enquadra outros eventos não formais como debates públicos. Este aumento dos níveis profissionais é também destacado nos trabalhos de Ferreira (2005) e destacado em Sarmento (2008).

Ao fluxo de dinheiro estrangeiro que entra num país chama-se 'entrada de divisas'. Estas podem ser através de exportações, empréstimos, aplicações em bolsas de valores, remessas de empresas nacionais no estrangeiros, remessas de particulares emigrados, de forma mais direta

10 Sociedade de Desenvolvimento Turístico das Ilhas das Boa Vista e Maio. 
através de tributação de serviços aduaneiros ou ainda através da requisição de um visto de turismo. De acordo com o Banco de Cabo Verde, tanto o investimento direto estrangeiro como as receitas brutas do turismo, entre elas milhões em vistos de turismo, foram e são significativos. Apesar de existir uma tendência atual para uma redução do investimento e uma crescente receita do turismo o que mantém a ideia de que existiu e continua a existir de facto uma entrada enorme de divisas que pode novamente fazer crescer o investimento se novos empreendimentos hoteleiros forem edificados. O WTTC afirma que em 2014 o investimento específico em turismo rondou os $23,1 \%$ do total do investimento no país, o que se traduziu em 15,4 mil milhões de Escudos de Cabo Verde (ECV) ou 147,8 milhões de euros ${ }^{11}$.

Esta ilha dependia até há poucas décadas da agricultura de subsistência, pastorícia e da pesca artesanal. Estas são algumas das práticas tradicionais mais importantes, mas poderíamos incluir aqui outras como a recoleção de sal, urzela, cal, cerâmica, entre outras já (praticamente) extintas. Existem atualmente exemplos de 'revitalização das práticas tradicionais', como o caso da pesca e da agricultura. Esta revitalização é um dos impactos positivos mencionados e pouco comum na maioria dos estudos internacionais, ainda assim partilhado pelo trabalho de DeKadt (1979).

Seguidamente temos a 'proteção ambiental', que engloba todo o tipo de investimento público ou privado na criação e manutenção de áreas protegidas, incluindo campanhas ambientais e todo tipo de legislação que visa a proteção do ecossistema natural da ilha. Desde organismos públicos do Governo à Câmara Municipal, até associações de proteção ambiental ou de capacitação de jovens. Este impacto é considerado por Ferreira (2005) nos seus trabalhos. A Boa Vista contém 14 das 47 áreas protegidas do país, entre elas sete reservas em ilhéus, quatro monumentos naturais e duas paisagens, abrangido área terrestre como marítima, sobretudo a leste da ilha, sendo algumas destas áreas protegidas se sobrepõem a zonas de desenvolvimento turístico.

Finalmente, temos a 'procura por artesanato' local ou tradicional, um impacto bastante comum e que se prende com o desejo da parte dos turistas em consumir objetos que representam a arte e cultura do local visitado ( Liu e Var, 1986; Ap e Crompton, 1998).

11 Tais dados vão ao encontro dos trabalhos de Ferreira (2005). 
Abaixo, os impactos positivos do turismo percecionados pela comunidade residente da Boa Vista e o respetivo número de menções:

Tabela 1: Impactos Positivos do Turismo Percecionados em Número de Menções

\begin{tabular}{|l|r|}
\hline \multicolumn{1}{|c|}{ Impactos Positivos Percecionados } & N $^{\mathbf{0}}$ de Menções \\
\hline Criação de Emprego & 64 \\
\hline Infraestruturação & 48 \\
\hline Migração & 46 \\
\hline Melhoria das Condições de vida & 33 \\
\hline Crescimento Económico & 25 \\
\hline Intercâmbio Cultural & 17 \\
\hline Aumento dos Níveis Profissionais & 15 \\
\hline Entrada de Divisas & 11 \\
\hline Revitalização das Tradições & 5 \\
\hline Proteção Ambiental & 3 \\
\hline Procura por Artesanato & 1 \\
\hline TOTAL & 268 \\
\hline
\end{tabular}

Fonte: autor

\section{Impactos Negativos Percecionados pelos Residentes}

Uma outra questão basilar desta investigação era determinar, de acordo com as perceções dos entrevistados, quais os impactos negativos que o turismo massificado havia trazido para a ilha da Boa Vista. Se nos impactos positivos a esfera económica dominou, desta vez foram os impactos de cariz social. Estes representam $63 \%$ dos impactos negativos, sublinhando que as questões sociais negativas trazidas pelo turismo massificado ocupam lugar de destaque nas perceções dos indivíduos entrevistados. Seguidamente foram os impactos negativos associados à economia com $29 \%$ e, por fim, os impactos negativos intimamente ligadas ao ambiente $(8 \%)$.

Como será de notar, alguns destes impactos são muito próximos de impactos positivos anteriormente tratados, e noutros casos até o reverso destes, o que demonstra a panóplia de diferentes e até contraditórias perceções que coabitam entre os entrevistas, e que enriquecem esta investigação e seus resultados. Como fizemos até agora, iniciaremos pelo mais vezes mencionados e continuaremos por ordem decrescente.

O primeiro impacto negativo é o 'aumento da criminalidade', e engloba na realidade um conjunto vasto de impactos como a prostituição, assaltos à mão-armada, assaltos a casas, 
homicídios, venda e consumo de drogas, violência de gangues e um conjunto de atos considerados como criminosos, chegando ainda até à simples noção ou "sensação de insegurança" percecionada pelos entrevistados. Estes resultados são comuns na literatura internacional dedicado ao tema como atestam os trabalhos de Nicholls (1976) e Cohen (1988), e são associados, pelos entrevistados, ao aparecimento e expansão das chamadas barracas, o bairro da 'Farinação' e o bairro da 'Boa Esperança', e correlacionado com o 'crescimento descontrolado', e com outros impactos negativos.

Para os residentes da Boa Vista existe uma 'divisão desigual dos benefícios entre a comunidade local', nomeadamente, entre os residentes nativos da Boa Vista e os novos residentes estrangeiros. Esta distribuição desigual deve-se, para os entrevistados, com o facto dos investidores estrangeiros retirarem maiores dividendos do turismo que os nativos do país e da ilha. A maioria da insatisfação prende-se com o facto dos hotéis serem do tipo tudoincluído, retirando inúmeras oportunidades de negócio aos locais que, por sua vez, possuem pequenos negócios ligados ao comércio e serviços.

Ora, por 'crescimento descontrolado' entendemos um crescimento da população residente e visitante, acima da capacidade de carga do destino, nomeadamente, ao nível de infraestruturas, serviços básicos e outros garantidos pela constituição de Cabo Verde aos seus cidadãos e residentes legais. O exemplo icónico deste tipo de descontrolo é o da malha urbana, mormente o surgimento e expansão exponencial dos bairros de lata ilegais da cidade de Sal-Rei, concretamente o bairro da Boa Esperança e o bairro da Farinação. O grande foco de crítica são, sem dúvida, estes bairros degradados sem acesso a serviços básicos como água potável canalizada e saneamento básico, na sua maioria sem acesso à rede elétrica (de forma legal ou ilegal), recheado de habitações e pequenos negócios situados em condições precárias de segurança e higiene. Lugares que dependem de cisternas públicas e que provocam filas diárias para a obtenção de água potável para consumo e higiene pessoal, e onde presença das forças públicas policiais é, apesar de gradualmente mais presente, ainda reduzida.

Por crescimento descontrolado incluímos ainda, o investimento em infraestruturas dedicadas ao turismo por parte de privados, ou ainda, os grandes empreendimentos hoteleiros do tipo resort ou residências em condomínio fechado que ficam por terminar devido a questões de litígio legal, retração de investidores, entre outros fatores. 
O 'aumento dos preços' é um outro impacto comum em espaços turísticos dada a inflação a que esses lugares estão sujeitos, em particular os espaços de maior sucesso. Deve-se notar que no caso da ilha da Boa Vista, esta desde à muito padece de uma periferia face aos principais centros de produção, sobretudo agrícola, o que inflaciona os preços dos produtos, em particular os básicos. O 'aumento dos preços' é sinónimo também de degradação da qualidade de vida, estabelecendo desde logo um paradoxo com o impacto positivo já analisado que determinava exatamente uma melhoria da mesma qualidade. Este impacto negativo está presente tanto em Carmichael et al (1996) e em Lawson e Williams (2001), assim como em inúmeros outros trabalhos.

Se é indiscutível que a cultura de qualquer sociedade é mutável, sofrendo ajustes constantes aos seus códigos de conduta, moralidade, regras e valores, não deixa de ser justo salvaguardar que estas mutações podem ocorrer a ritmos muito diferentes de uma sociedade para outra. São as transformações percecionadas como aceleradas que ocorreram na comunidade da Boa Vista que classificamos de forma lata como 'alterações à moralidade'. Transformações forçadas, por um lado, pela interação de diferentes gentes e culturas no mesmo espaço, por outro, pela modernização acelerada a que o espaço e as suas gentes foram forçadas pela mão do turismo, nomeadamente o massificado. Apesar destas alterações não ocorreram apenas entre as comunidades nativas da ilha, isto é, reconhecendo que existe uma influência mútua de, para, e entre as várias culturas, há que reconhecer que algumas exercem uma pressão superior em relação a outras. Na Boa Vista as perceções mostram uma clara pressão exógena, nacional como estrangeira, sobre a comunidade nativa. Esta 'alteração da moralidade' está presente também nos trabalhos de referência de autores como Brunt e Courtney (1999) e Tomljenovic e Faulkner (2000) sendo uma das principais armas de arremesso teórico nas obras que mais atacam o turismo internacional como a obra de Turner e Ash (1975) é exemplo.

Como já Kousis (1989), Brayley et al (1990) e Freitag (1994) haviam contemplado a 'exploração laboral' é um impacto negativo comum do turismo. Os entrevistados apontaram para a existência de uma atitude discriminatória como fruto das alterações provocadas pela chegada do turismo massificado, ou seja, a forte migração para a ilha de membros de comunidades de outras ilhas do arquipélago e de outros países também teve consequências negativas, entre elas um acentuar do discurso e atitude discriminatória da população local face à nova população migrante. A 'discriminação face aos migrantes', é um discurso que resulta 
também da revolta de muito imigrantes caboverdianos que acusam os nativos de inveja que resulta da sua passividade na procura de trabalho. De facto o pivô do discurso discriminatório está assente nas questões laborais. A génese da revolta parece ser sempre a questão em torno das oportunidades de trabalho que parecem escapar aos nativos, em parte o que já apontámos no segundo impacto negativo. A 'discriminação face aos migrantes' é um aspeto particular da Boa Vista, não apenas pelas suas características, mas também porque tal impacto negativo não encontra eco na literatura de referência.

A 'especulação imobiliária', ou seja, o aumento dos preços dos bens imobiliários, como habitações e terrenos, do simples aumento de $\operatorname{preços}^{12}$, de acordo com os dados recolhidos, deveu-se a dois fatores interligados, mas que devem ser considerados separadamente. Por um lado, os terrenos tiveram enorme procurada por parte de investidores estrangeiros para a construção de infraestruturas hoteleiras e de habitações de férias, como apart-hotéis e condomínios, para venda no mercado Europeu. Por outro lado, o aumento populacional e a carência de habitações suficientes agravou a procura interna e fez subir drasticamente o custo das habitações e respetivo aluguer, o que por arrasto dificultou o acesso dos nativos da Boa Vista aos terrenos, que anteriormente eram facilmente adquiríveis.

A 'ausência e/ou inadequação de infraestruturas' surge na décima posição dos impactos negativos percecionados, e refere-se às infraestruturas básicas, ou serviços básicos, especificamente: a rede de esgotos ou saneamento, água canalizada, eletricidade, recolha e gestão de lixo. A pressão de consumo de água e de outros recursos de forma excessiva (para a capacidade atual) por parte das grandes cadeias hoteleiras dificulta e atrasa o abastecimento das populações residentes. Para agravar a situação deve-se recordar que o consumo de qualquer dos hotéis de turismo massificado da ilha é superior a toda a população residente, o que acaba por colocar a prioridade da empresa privada nos seus principais clientes, os grandes hotéis. A inadequação das infraestruturas é resultado do consumo excessivo de recursos, escassos, que por sua vez deriva do aumento exponencial da população residente e visitante, daí que este impacto é muitas vezes catalogado como 'consumo excessivo de recursos',

12 Determinou-se que o número de menções específicas a este tipo de aumento de preços exigia o seu destaque, nessa medida não podemos destacar este impacto como sendo necessariamente diferenciador face aos estudos internacionais apesar da sua demarcada presença. Esta distinção baseou-se ainda, em parte, pelo facto de surgir antes mesmo da implementação do turismo massificado apesar de com ele, e depois dele, se ter agravado. 
estando por exemplo presente nos trabalhos de Ferreira (2005), entre muitos outros.

Desde o ponto de vista dos entrevistados, a chegada de turistas trouxe uma procura por bens de consumo, entre eles os produtos de artesanato, sendo que estes são quase exclusivamente produzidos e vendidos por nacionais do Senegal e de outros países do continente africano. Os entrevistados consideraram esse facto como um exemplo de perda de 'autenticidade cultural', já que consideram que é artesanato oferecido não os representa. A autenticidade cultural é um impacto negativo presente em trabalhos como os de Brougham e Butler, (1981), e Dogan (1989), no entanto, há que referir que este impacto refere-se, na sua maioria, especificamente à adulteração dos objetos culturais tradicionais da ilha da Boa Vista, e não necessariamente a outras alterações de cariz social ou comportamental.

Com a injeção acentuada de capital na economia nacional e local tornar-se expectável que forças políticas decisórias possam cair na tentação de facilitar caminhos e permitir atalhos em troca de géneros, e sobretudo, dinheiro. Não obstante a 'corrupção' implica a participação de corruptor e de corrupto, e assim, não são apenas os elementos políticos decisores que devem arcar com todas as atenções. As entrevistas acusam os políticos, em particular os responsáveis políticos regionais. A 'corrupção' é sem dúvida um impacto que vive emparelhado com o crescimento económico ou pelo menos com a sua perspetiva, mas no caso desta investigação, até porque não era esse o seu objetivo, foi possível determinar se esta perceção era um reflexo fidedigno da realidade.

Dado que não existem elementos comparativos não podemos falar em 'declínio da atitude dos locais face ao turismo ${ }^{13}$, ainda assim os dados apontam para uma insatisfação. Na Boa Vista, os residentes manifestaram insatisfação pela presença do turismo e dos turistas. Esta insatisfação está relacionada com a expetativa inicial que os mesmos e a comunidade em geral tinham, sobretudo os nativos da ilha.

A ausência do setor secundário e a insipiência do setor primário, na ilha da Boa Vista, forçaram a aposta no setor terciário, os serviços, nomeadamente, num tipo específico de serviço, o turismo. Atualmente, de acordo com os entrevistados, existe uma dependência acentuada face ao turismo, aliás, poder-se-ia falar em dependência nacional, uma vez que as divisas e impostos que proveem diretamente dos turismo têm sido capazes de equilibrar as

13 O declínio da atitude é abordado em obras como Doxey (1975) ou Dogan (1989). 
contas nacionais e melhorar dramaticamente o produto interno bruto de Cabo Verde. Ferreira (2005) sublinhou a 'dependência face ao turismo' como um importante impacto negativo que deve ser abordado com a máxima importância e atenção dada a fragilidade ambiental e económica dos destinos turísticos (em particular os balneares).

O 'aumento da poluição', é também um impacto negativo e está relacionado com as questões ambientais e a 'ausência de infraestruturas básicas'. Obviamente que não havendo, por exemplo, uma lixeira devidamente preparada e equipada para tratar as toneladas de lixo que são despejadas diariamente, essa poluição torna-se rapidamente um problema grave com consequência a curto e a longo prazo. Recorde-se que a lixeira encontra-se precisamente sobre a maior bacia hidrográfica do país e assim numa posição delicada tanto para humanos como o resto do ecossistema autóctone que depende dessa água e terrenos férteis adjacentes. A poluição que advém da lixeira é o principal alvo das críticas dos entrevistados. O 'aumento da poluição' é sem dúvida um dos impactos negativos mas comuns na literatura, como por exemplo em Jurowski e Gursoy (2004) ou Northcote e Macbeth (2005). A fragilidade ambiental dos destinos e/ou a sobre-população dos espaços e do consumo dos recursos acabam por acarretar esta consequência que em muitos casos acaba por levar ao declínio de um destino.

A 'perda de direitos dos residentes' é o próximo impacto negativo percecionado e remete-nos para a questão da privatização de algumas praias públicas por parte dos grandes hotéis. Esta exclusão de cidadãos caboverdianos a praias anteriormente públicas teve o seu exemplo mais significativo aquando da construção do hotel Marine Club, que bloqueou o acesso a parte de uma praia anteriormente utilizada pelos locais. Agravando ainda mais a situação o dito hotel bloqueou o acesso à antiga praia de Fátima onde estão as ruínas de uma igreja negando assim o acesso à igreja durante uma procissão anual o que levou a protestos de indignação. De forma a contornar a situação foi criado uma caminho pedestre que rasga o hotel e permite a dita procissão e o acesso às praias localizadas do outro lado do hotel. Northcote e Macbeth (2005) também descortinaram no seu estudo como os residentes haviam perdido direitos para os operadores e/ou turistas. Estes podem tomar várias formas, entre elas direitos sobre território, acesso a recursos, e direitos laborais.

Já presente nos trabalhos de Cater (1987) como de Faulkner e Tideswell (1997), a 'destruição 
da natureza' é o próximo impacto negativo percecionado. Como será claro, considerámos referências à destruição do ecossistema da Boa Vista, nomeadamente, as suas dunas e praia, mas também as espécies endógenas da ilha como as tartarugas, baleias e algumas aves que correm risco de extinção ou de excesso de consumo como as lagostas, o atum ou o peixe serra. Ainda que esta possa ser mitigada até certa medida, a simples ocupação dos espaços para edificação de infraestruturas de suporte à atividade turística obriga à destruição da natureza.

Mathieson e Wall (1982) foi um dos primeiros autores a constatar como o turismo poderia promover 'alterações nos padrões de consumo' das comunidades anfitriãs, seja esta promovida pelo aumento dos preços ou escassez de recursos, ou pelo efeito demonstrativo que DeKadt (1979) salientou. Este foi precisamente o sucedido na Boa Vista, e hoje os seus nativos afirmam serem forçados a consumir, por exemplo, diferentes tipo de peixe em virtude da procura e do preço de algumas das espécies anteriormente mais consumidas.

Nesta investigação uma percentagem reduzida dos entrevistados menciona a 'perda da língua local' devido à multidão de residentes e visitantes de outras paragens. Promovendo uma perda do uso e importância da língua local, para línguas dos países visitantes e variações da língua nacional não oficial, o crioulo, e oficial, o português. Impacto negativo já identificado nos trabalhos de White (1974) e Coppock (1977).

Por fim, o último impacto negativo mencionado pelos entrevistados é o 'abandono das práticas tradicionais ${ }^{14}$. Sem dúvida contraditório visto que o número de pescadores e agricultores da ilha tem aumentado. A questão é levantada sobretudo por nativos da ilha que parecem remeter erroneamente a ausência de jovens autóctone nestas práticas como sinónimo da sua perda ou abandono.

O quadro que resume os impactos negativos do turismo percecionados pela comunidade residente da Boa Vista e o respetivo número de menções:

14 Impacto negativo focado nos trabalhos de Ferreira (2005). 
Tabela 2: Impacto Negativos do Turismo Percecionados em Número de Menções

\begin{tabular}{l|r|}
\multicolumn{1}{|c|}{ Impactos Negativos Percecionados } & $\mathbf{N}^{0}$ de Menções \\
\hline Aumento da Criminalidade & 64 \\
\hline Divisão Desigual dos Benefícios & 59 \\
\hline Crescimento Descontrolado & 56 \\
\hline Aumento dos Preços & 55 \\
\hline Alterações à Moralidade & 41 \\
\hline Exploração Laboral & 29 \\
\hline Discriminação aos Migrantes & 28 \\
\hline Especulação Imobiliária & 22 \\
\hline Ausência de Infraestruturas & 19 \\
\hline Perda da Autenticidade & 17 \\
\hline Aumento da Corrupção & 14 \\
\hline Atitude dos Locais face Turismo & 11 \\
\hline Dependência face ao Turismo & 11 \\
\hline Aumento da Poluição & 10 \\
\hline Perda de Direitos dos Residentes & 7 \\
\hline Destruição da Natureza & 7 \\
\hline Alteração Padrões Consumo & 4 \\
\hline Perda da Língua Local & 3 \\
\hline Abandono das Práticas Tradicionais & 2 \\
\hline TOTAL & 459 \\
\hline
\end{tabular}

Fonte: autor

\section{Conclusão}

Seguindo o modelo de desenvolvimento centrado no mercado externo e na oferta de serviços turísticos, Cabo Verde procura o equilíbrio das suas finanças na atividade turística. Organismos internacionais, como a Organização Mundial do Turismo, encorajam os países em vias de desenvolvimento a procurar nesta atividade a solução para grande parte dos seus problemas de capitalização. No entanto, as suas consequências negativas podem ser muito superiores ás positivas se as comunidades não disporem de estruturas, ferramentas e conhecimentos adequados para as prevenir ou mitigar.

São inegáveis as vantagens de uma aposta de fundo na atividade turística, assim como as suas desvantagens. Da literatura de referência, com várias décadas de trabalho acumulado, aos discursos quotidianos das comunidade afetadas, apenas surpreendem quem os ignora ou desconhece. Enquanto palco privilegiado da aposta turística e, por arrasto, do desenvolvimento de toda uma nação insular, a ilha da Boa Vista parece ser um excelente 
exemplo de como as precariedades de base de uma comunidade, se podem tornar profundos e graves impactos negativos que assolam toda uma população.

A Boa vista é exemplo de como o turismo pode trazer consequências positivas a uma comunidade, em particular, do tipo económico como: emprego, melhoria da qualidade de vida, infraestruturação, crescimento económico, qualificação profissional, etc. Por outro lado, é também exemplo de muitas consequências negativas que, se forem ignoradas, conduzem a uma deterioração da comunidade recetora, mormente, do tipo social e ambiental como: aumento da criminalidade, dos preços, da poluição, bairros degradados, etc.

Desde a perspetiva estrita das perceções da comunidade residente, o desdobramento de perceções erróneas e/ou potencialmente degenerativas da realidade, se continuamente ignorado e/ou não corrigido, pode conduzir a um posicionamento face ao turismo gradualmente menos positivo. A disparidade quantitativa entre os impactos negativos e positivos percecionados não é sinónimo imediato de um desfalque na balança da atividade turística num destino, sua comunidade, e meioambiente. No entanto, neste estudo de caso, determinou-se que, desde a perspetiva dos membros da comunidade boavistense, parece de facto o que ocorre. Resta realizar uma avaliação formal, profunda e transparente à atividade turística na ilha para determinar em que medida tais perceções se podem, ou não, aproximar da realidade dos factos.

\section{Referências}

AKIS, S.; PERISTIANIS, N.; WARNER. J. Residents' attitudes to tourism development: the case of Cyprus. Tourism Management, vol.17, p.481-494, 1996.

ANDRIOTIS, K. Integrated resort development: The case of Cavo Sidero. Crete. Journal of Sustainable Tourism, vol.16, n.4, p.428-444, 2008.

AP, J.; CROMPTON, J. Developing and Testing a Tourism Impact Scale. Journal of Travel Research, vol.37, n.2, p.120 - 130, 1998.

BERTRAM, G. The MIRAB model twelve years on. The Contemporary Pacific, vol.11, n.1, p.105-38, 1999.

BRAYLEY, R.; VAS, T.; SHELDON, P. Perceived influence of tourism on social issues. Annals of Tourism Research, vol.17, n.2, p. 84-289, 1990.

BROUGHAM, J.; BUTLER, R. A segmentation analysis of resident attitudes to social impacts of tourism. Annals of Tourism Research, vol.7, n.4, p.569-90, 1981. 
BRUNT, P.; COURTNEY P. Host Perceptions of Sociocultural Impacts. Annals of Tourism Research, vol.26, n.3, p.493-515, 1999.

CARMICHAEL, B.; PEPPARD, D.; BOURDREAU, F. Mega-resort on my doorstep: Local residents' attitudes toward Foxwood Casino and Casino Gambling on nearby Indian Reservation Land. Journal of Travel Research, vol.34, n.3, p.9-16, 1996.

CATER, E. Tourism in the least developed countries. Annals of Tourism Research, vol.14, n.2, p.202226, 1987.

CHEN, Chih-Chien, Deepak CHHABRA, Kevin TATSUGAWA (2004), "Resident Perception of the Effect of Tourism A Case Study", e-Review of Tourism Research (eRTR), 2(4), pp. 82-87.

COHEN, E. Traditions in the Qualitative Sociology of Tourism, Annals of Tourism Research, vol. 15, p.29-45, 1988.

COOKE, K. Guidelines for Socially Appropriate Tourim Development in British Columbia. Hospitaity, Leisure, Sport \& Tourism, vol.21, n.1, p. 22-28, 1982.

COPPOCK, T. Second Homes: Curse or blessing?, Oxford: Pergamon Press, 1977.

DEKADT, E. Tourism: A Passport to Development?, New York: Oxford University Press, 1979.

DOGAN, H. Forms of adjustment: sociocultural impacts of tourism. Annals of Tourism Research, vol.16, n.2, p.223-239, 1989.

DOXEY, G. A causation theory of visitor-resident irritants methodology and research inferences. Sixth Annual Conference, Proceedings of Travel Research Association, vol.32, p.29-34, 1975.

FAULKNER, B.; TIDESWELL C. A Framework for Monitoring Community Impacts of Tourism", Journal of Sustainable Tourism, vol.5, n.1, pp.3-28.1997

FERREIRA, L. Estudo Analítico das Variáveis da Macro Envolvente de uma Destino Turístico. Revista de Estudos Politécnicos, vol.2, n.4, pp.135-147, 2005.

FILHO, J. Cabo Verde: Apontamentos Etnográficos, Lisboa: Edições do autor, 1976.

FREITAG, T. Enclave Tourism Development for Whom the Benefits Roll? Annals of Tourism Research, vol.21, n.3, p.538-554.1994

GU, H.; RYAN, C. Place Attachment, identity and community impacts of tourism: the case of Beijing Hutong”, Tourism Management, vol.29, n.4, p.657-647, 2008.

INE-CV, Instituto Nacional de Estatística de Cabo Verde, (www.ine.cv), 2015.

JUROWSKI, C.; Dogan, G. Distance effects on residents' attitudes toward tourism. Annals of Tourism Research, vol.31, n.2, p.296-304, 2004.

KOUSIS, M. Tourism and the family in a rural Cretan community. Annals of Tourism Research, vol.16, n.3, p. 318-332, 1989.

LAWSON, R.; J. WILLIAMS, J.; TOUNG, T.; COSSENS, J. A comparison of residents' attitudes towards tourism in 10 New Zealand destinations. Tourism Management, vol.19, n.3, pp. 247-256, 1998. 
LIMA, A. Boavista: Ilha de Capitães (História e Sociedade), Praia: Spleen Edições,1997.

LIMA, A. Boavista, Ilha da Morna e do Landú, Praia: Instituto Superior da Educação, 2002.

LIU, J.; VAR, T. Resident Attitudes towards Tourism Impacts in Hawaii. Annals of Tourism Research, vol.13, n.2, p.193-214, 1986.

MATHIESON, A.; WALL, G. Tourism Economic Physical and Social Impacts. Longman: England, 1982.

MILMAN, A.; PIZAM, A. Social impact of tourism on Central Florida. Annals of Tourism Research, vol.15, n.2, p.191-204, 1988.

MONTERRUBIO, J.; GULLETTE, G.; MENDONZA-ONTIVEROS, M.; FERNÁNDEZ, M.; LUQUE, A. Social Impacts of Tourism as Perceived by State-planned Tourism Destination Residents: the case of Huatulco, Mexico", International Journal of Tourism Anthropology, vol.2, n.1, p. 34-52, 2012.

NEVES, J. Estado da Nação - Construindo a Prosperidade para Todos. Discurso do Estado da Nação na Assembleia Nacional, 2010. Disponível em: www.governo.cv/documents/Estado da Nacao.pdf. Acesso em: 8 Jan. 2015.

NICHOLS, L. Tourism and Crime. Annals of Tourism research, vol.3, p.81-176, 1976.

NORTHCOTE, J.; MACBETH, J. Conceptualizing yield: Sustainable Tourism Management. Annals of Tourism Research, vol.33, n.1, p.199-220, 2005.

PERDUE, R.; LONG, P.; ALLEN, L., Resident Support for Tourism Development. Annals of Tourism Research, vol.17, n.4, p.586-599, 1990.

POIRINE, B. A Theory of Remittances as an Implicit Family Loan Arrangement. Two Essays on Aid and Remittances, Pacific Studies Monograph 19, Sydney, Centre for Pacific Studies, University of New South Wales, 1995.

SARMENTO, E. O Turismo Sustentável como factor de desenvolvimento das pequenas economias insulares: o caso de Cabo Verde. Lisboa: Edições Universitárias Lusófonas, 2008.

TOMLJENOVIC, R.; FAULKNER, B. Tourism and World Peace: A Conundrum for the Twenty-first Century. IN: Faulkner et al (Eds.), Tourism in the Twenty-first Century, London: Continuum, 2000.

TURNER, L.; ASH, J. The golden hordes: International tourism and the pleasure periphery, Constable: London, 1975.

WHITE, P. The Social Impact of Tourism on Host Communities: A Study of Language Change in Switzerland, Oxford: Oxford University Press, 1974.

WTTC, World Travel and Tourism Council Cape Verde Annual Report at https://www.wttc.org//media/files/reports/economic\%20impact\%20research/countries\%202015/capeverde2015.pdf, 2015.

\section{Recebido em: 08/01/2015 (1 ${ }^{\mathrm{a}}$ versão) $22 / 11 / 2015$ ( $2^{\mathrm{a}}$ versão)}

